(b.) The construction of the intakes in such a manner that surface water should not find its way into the pump wells at the pumping stations. This precaution indeed should be observed on the Delaware River as well.

(c.) The thorough aeration of the water followed by storage and sedimentation in reservoirs of large capacity, properly cleansed at reasonable intervals.

(d.) The removal of earthy and other suspended impurities by the application of suitable methods of filtration, so that the water may be rendered at all times clear and limpid.

5th. In the selection of a new water supply for the city of Philadelphia, the Blue Monntain tributaries of the Delaware and Lehigh rivers are to be preferred before all others. And whilst of the Delaware River waters, that at the Water Gap is entitled to the first place, that gathered at Byram (Point Pleasant) is uniformly wholesome and of satisfactory purity and quality.

\title{
NOTES ON SOME SANITARY EXAMINATIONS OF WATERS.
}

\section{BY E. W Aller, Ph.D.}

Croton W WTER.

The results of a semi-montbly examination of the Croton water for the past year are herewith presented as being possibly of some interest to the members of the Society.

In contrasting the results for the last half of 1885 with those given by Prof. Breneman (this journal Vol. VIII., 1) for the same period, some differences are noticeable, no doubt due to differences of manipulation, as well as to difference in location. It may therefore be advisable to state the methods used, though they contain nothing novel.

For chlorine one litre of the water was evaporated down to small bulk before making the titration with silver nitrate in the usual manner. By a series of experiments I satisfied myself that a small error was introduced by directly titrating waters as weak in chlorides as the Croton without evaporation. The results on evaporating one litre were, however, found to be identical with those obtained 
SANITARY EXAMINATIONS OF WATERS.

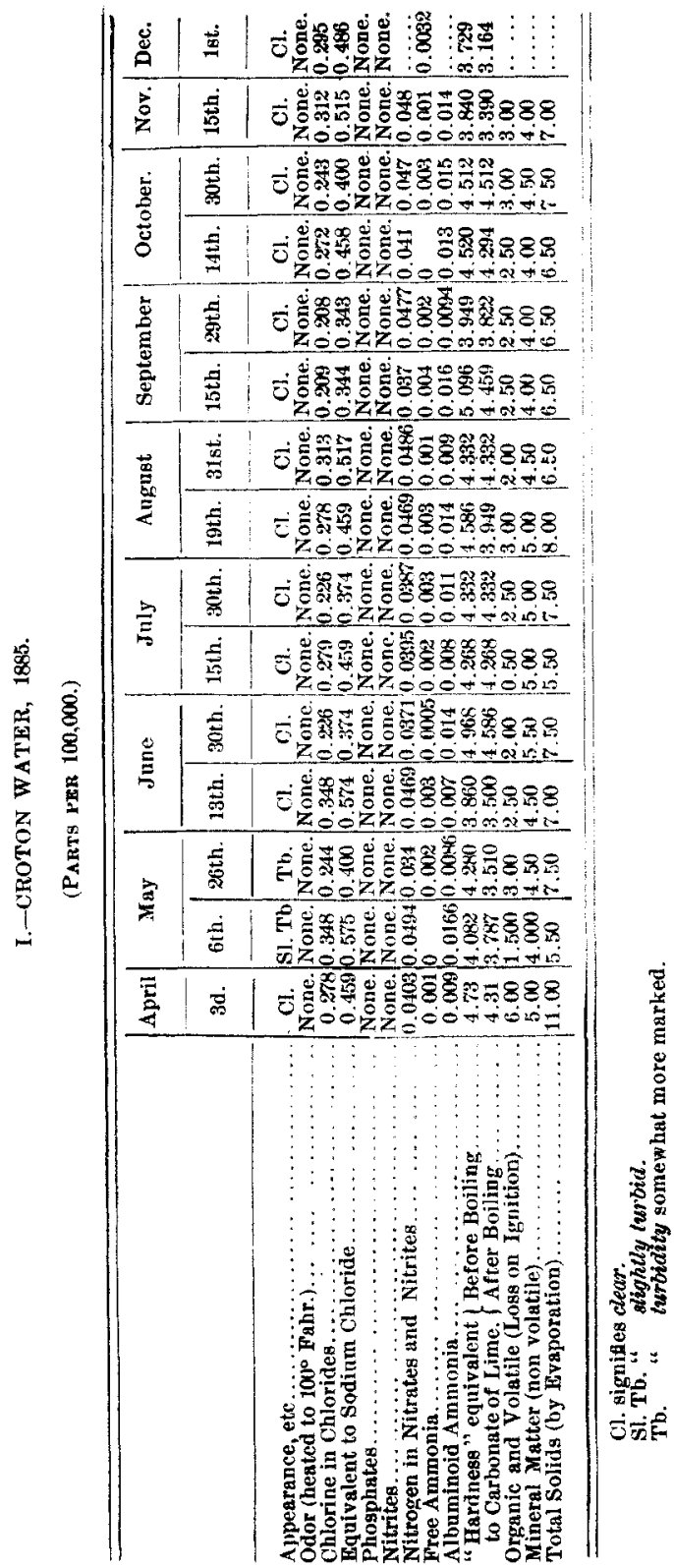




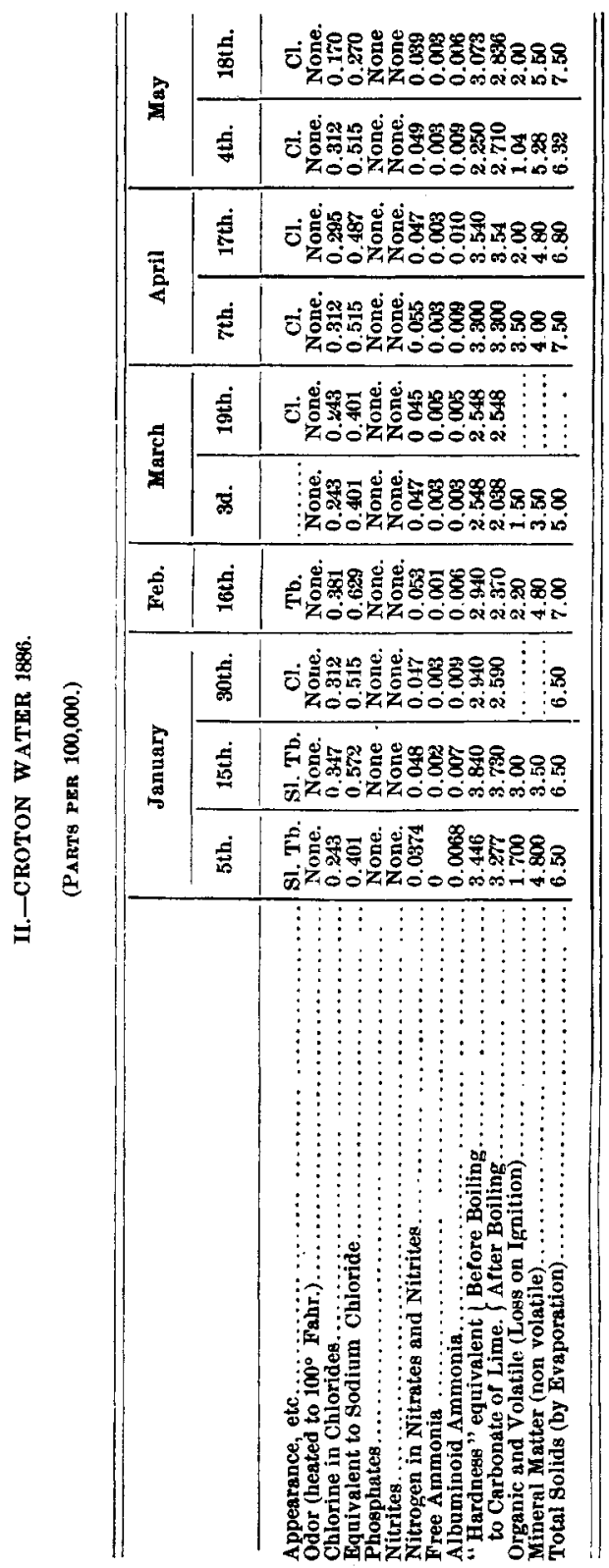


by evaporating ten litres. The error seemed to be in part due to the bicarbonates present, as well as to the amount of silver salt required to show the end reaction distinctly.

For the ammonia my practice is to first introduce into a retor: of about one litre capacity $250 \mathrm{cc}$. to $500 \mathrm{ec}$. of some water (usually Croton), together with the proper quantity of the reagent to set free the ammonia (sodium carbonate solution for free, or potassium hydrate and permanganate solution for total). Then to apply heat and distil until the distillate is absolutely free from ammonia. This is usually more rapidly brought about when permanganate is used, the longer the alkaline permanganate solution has been standing. I prefer always to keep it standing for a month if possible. When no ammonia shows in the 50ce. of the distillate, $500 \mathrm{cc}$. of the water to be tested is added, and distillation is resumed, the distillates being caught in successive $50 \mathrm{cc}$. portions. Three or four portions are run off for free and five or six for "total" before nesslerizing is commenced, and then the nessler solution is added simultaneonsly to the distillates and comparison tubes, and the ammonia estimated. With Croton the second distillate in the case of free, and the fourth in the case of "total," usually can show little or no color. The difference between "total" and free is recorded as albuminoid ammonia.

Prof. Breneman's results agree with my own very well during the cold months, but differ by nearly 0.01 part per 100,000 in the warm months. The differencos are no doubt principally due to difference of procedure, though they suggest the possibility of the presence of a certain kind of nitrogenous matter, which may manifest itself in the method which he has pursued.

I have abandoned the idea of getting all the nitrogen from a water by the use of alkaline permanganate, but am at present trying some experiments with a view to the application of the Kjeldahl process to water analysis.

\section{Susquehavina River.}

Cooperstown, N. Y., is at the southern end of Lake Otsego, the head waters of the Susquehanna river. It has a population of 2,500 to 3,000 , which is much increased in Summer. Last Summer the number of visitors (non-residents) was estimated at about 1,000 . 
The present water works, which take the supply from the lake, are about six years old, the water company carrying on its business under an extension of an old charter granted to a company in 1827.

The intake is a ten inch main extending North into Lake Otsego for about half a mile to a place where the water is about 35 feet deep. The end of the main rests on crib work and the opening is turned downward so as to take the water at about five feet from the bottom. The main runs a short distance down the stream (Susquehanna river) from the lake to the pump house, where a small turbine, worked by the stream, forces the water directly into the mains by means of a Worthington pump. To the pump is attached a water governor, which can be adjusted to give any desired pressure in the mains up to 1,000 lbs. per square inch. The pressure usually maintained is $80 \mathrm{lbs}$.

The company has about four miles of mains, the largest of which is eight inches in diameter. Last Fall there were but 250 water takers, as the residents abandon their pet wells with great reluctance.

The cost of installation of the system is put at $\$ 35,000$ to $\$ 40,000$. The tariff is $\$ 8$ to $\$ 12$ for each dwelling house. The town has a system of sewers through the main streets, the sewage being discharged into the Susquehanna river below the pump house.

At the time the sample was taken (September, 1885) the lake was about two feet above its ordinary level for that season, and nearly up to the Spring water mark, owing to unusually frequent and copious rains. The sample, of which the analysis is given, was taken from a tap on one of the mains. At the same time a sample was taken from one of the wells in the town, the water of which was decidedly preferred by the owner to that from the public supply, and also a sample from a spring on the side of the hill to the East of the town, not far outside of the corporation limits.

In May, 1885, I also had occasion to examine the water of Susquehanna in the neighborhood of Wilkesbarre, $\mathrm{Pa}$., in connection with the outbreak of typhoid fever at Plymouth, a few miles further down the river. The results are also given by way of comparison, although the difference of season does not make the comparison of so great a value as if they were taken at the same time. 


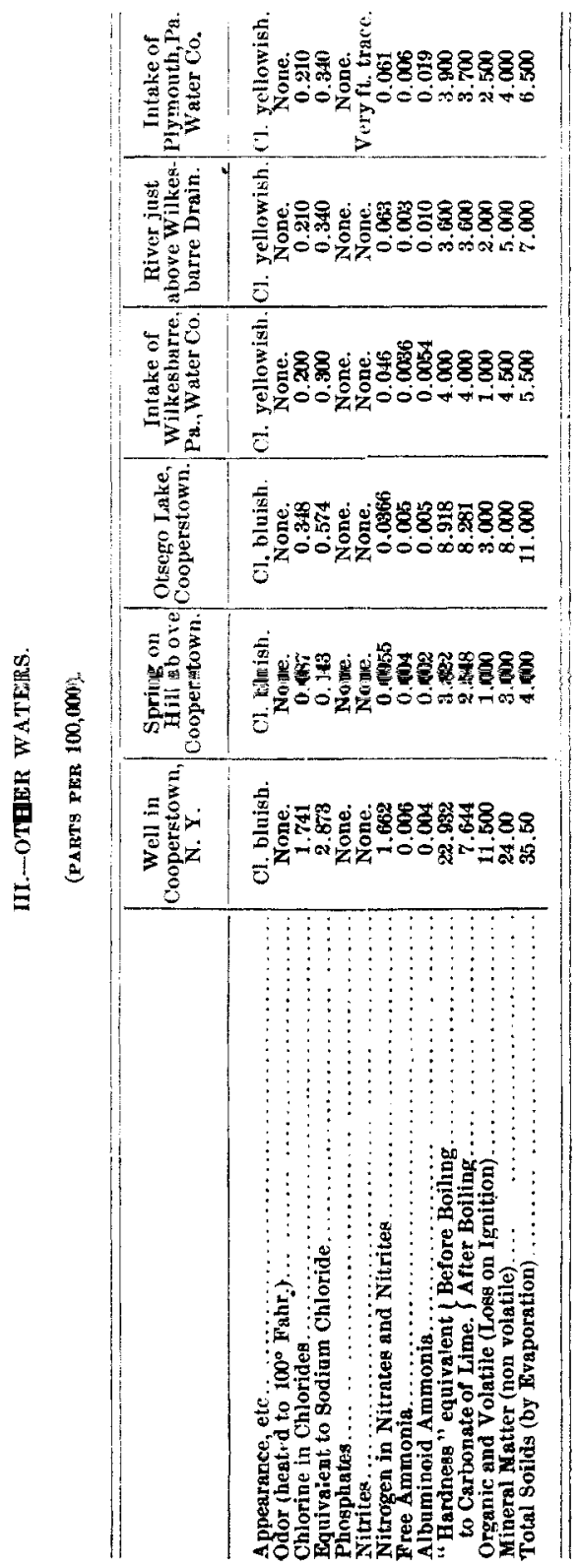




\section{Water from the Dismal Swamp.}

In November, 1884, while engaged in the examination of water from the wells of Manhattan Island, a sample of water was brought to me as though from one of those wells. A few tests satisfied me that such could not be the case. My suspicion that it was from the Dismal Swamp was afterward confirmed by an appeal to the gentleman who brought the sample to this city. He said that it had been sold about the streets of Washington as having mediciual properties. The results may be of interest. (Per 100,000.)

Appearince . . . . . . . . . . . . . . . . . . . . Clear coffee brown

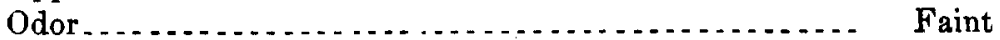

Chlorine in Chlorides . . . . . . . . . . . . .

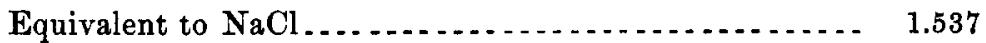

Phosphates.................................. None

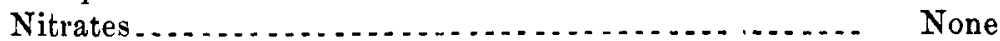

Nitrogen in Nitrates . . . . . . . . . . . . . . . . . . . . . . . 0.0805

Free Ammonia ................................... 0.0023

Albuminoid Ammonia............................. 0.0751

Hardness before boiling ........................... $\quad 2.480$

" after boiling .......................... 1.908

Organic and Volatile (loss on ignition) . ............ 9.400

Mineral Matter (non volatile) ........................ 4.000

Total Solids . . . . . . . . . . . . . . . . . . . . 13.400

Another sample of Dismal Swamp water, less highly colored, was received from Portsmouth, Va., about a month after. The sample was too small for a repetition of all the above tests. The results on evaporation of $100 \mathrm{cc}$. were :

Organic and Volatile (loss on ignition) $\ldots . . . . . . . . . .7 .500$

Mineral Matter (non volatile) ........ ................ $\quad 3.500$

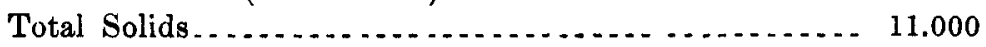

The color seemed to be about proportioned to the amounts of "organic and volatile."

In concentrating a litre of the water for the chlorine determination, a solution was obtained which was so strong in color that the end reaction with the chromate could not be seen. The addition of a minute fragment of alum, and filtering and washing hut, removed the coloring matter sufficiently for the purpose. The 
coloring matter so precipitated was, however, tolerably soluble n colder water.

Attempts have since been made to obtain a larger quantity of the water for the purpose of examining the character of the coloring matter, thus far without success.

The water from the Dismal $\mathrm{Swamp}$ is regarded as the most satisfactory in its sanitary aspects of any along the Atlantic coast, and ship captains prefer it over all others for fllling their water tanks when starting on a royage. The results obtained suggest most decidedly the mistakes that are frequently made by some chemists in applying the standards applicable only to well waters, to the water from ponds and streams, etc.

The dissimilarity of conditions require that very different standards should be applied, a point that is often neglected or lost sight of.

Water Supply of Ashevilie, N. C.

Ashville, N. C., is located among the mountains of Western North Carolina, about forty miles from the Tennessee boundary. Its elevation above the sea is about 2,500 feet. The place is incorporated as a city, its limits being a mile in every direction from the court house. Over this area, which includes many hills and dales, the dwellings are scattered. The place is one of resort for many Southerners in the Summer time, and is receiving attention as a location for Northern invalids in the winter, on account of its dry and equable climate during that season.

Beaucatcher Ridge, the Eastern limit of the valley of the French Broad River, overhangs the city. Into the side of this ridge, which consists of slate and more or less decomposed granite mixed with clay, has been dug an excavation, from which flows a small stream, which has been utilized as the water supply. The mains only supply an extremely limited district. The population of the city is put at 5,000 , for which the supply is altogether inadequate. In rainy weather the water is turbid from the presence of a finely divided clay, which takes days to settle out, while in dry weather the supply will not meet the demands of the few water takers that are there. On this account a more copious supply is to be introduced, and at the same time a system of sewers, which is at present lacking, is proposed. 
The results of the examination of the present supply may be of nterest, as showing the composition of a mountain water in that region, above all possibility of contamination. Sample taken Feb., 1886.

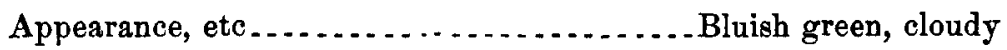

Odor, heated $100^{\circ} \ldots \ldots \ldots \ldots \ldots \ldots$ None

Chlorine........................................ 0.208

Equivalent to $\mathrm{NaCl} \ldots \ldots \ldots \ldots \ldots$

Phosphates................................. None

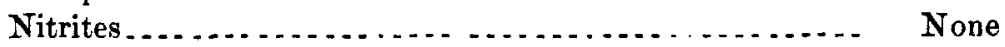

Nitrogen in Nitrates. . . . . . . . .

Free Ammonia . . . . . . . . .

Albuminoid Ammonia . . . . . . . . . .

Hardness .....

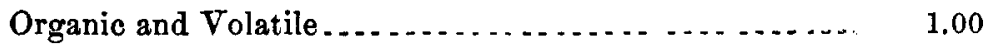

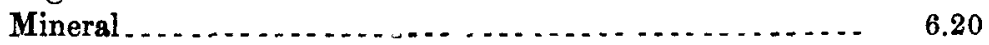

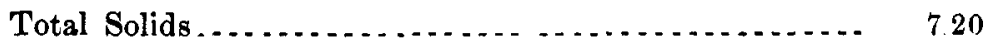

\section{NOTE ON THE EXAMINATION OF BUTTER FAT AND ITS SUBSTITUTES.}

\section{Br E. Whiler, Ph. D.}

The Reichert process* for the examination of butter fat and the substitutes therefor, commends itself to chemists on account of ease of execution, and constancy of results. Objections to it exist in the fact that it is so extremely arbitrary, and that the statement of results by it are incomprehensible to any but trained chemists. Notwithstanding this, many prefer it to the Hehner method, or the more generally used modification thereof the "Wash" process. As this last named method or its modification was the first fairly satisfactory method for the examination of butter fat, a strong prejudice naturally exists in favor of the form of report which states the percentages of insoluble, or of insoluble and soluble fat acids present.

I desire to propose a modification of the Reichert process, which seems to me to possess many advantages, premising that for butter fat and its substitutes the terms soluble and insoluble fat acids are practically synonymous with the terms volatile and non-volatile.

* Fres Zts., xviii., 68. 